Zeszyty Naukowe Szkoły Głównej Gospodarstwa Wiejskiego

Ekonomika i Organizacja Gospodarki Żywnościowej nr 120, 2017: 111-120

DOI 10.22630/EIOGZ.2017.120.42

Olena Kulykovets, Maria Jeznach, Anna Kudlińska-Chylak, Małgorzata Kosicka-Gębska

Wydział Nauk o Żywieniu Człowieka i Konsumpcji

Szkoła Główna Gospodarstwa Wiejskiego

\title{
Kształtowanie się rynku miodu w krajach Unii Europejskiej w latach 2001-2013
}

\section{Wstęp}

Produkcja miodu na świecie od 1961 roku systematycznie rośnie [Borowska 2011], a w 2011 roku wyniosła 1,6 mln t. Czołowym producentem są Chiny, a na drugim miejscu znajdowała się Unia Europejska (UE). Średnioroczne tempo wzrostu produkcji w UE było na poziomie $2 \%$, czyli niższym niż dla całego rynku miodu $(2,62 \%)$. Stanowi to zachętę do podjęcia działań zmierzających do polepszenia lub chociaż utrwalenia pozycji krajów UE na światowym rynku miodu.

\section{Cel pracy, materiał źródłowy}

Celem pracy jest próba przedstawienia zmian na rynku miodu w krajach UE w latach 2001-2013. Materiał do zaprezentowanych analiz stanowiły wtórne dane, w tym dane z bazy Faostat, roczniki statystyczne GUS, opracowanie GUS Budzety gospodarstw domowych za lata 2002-2013, opracowania Oddziału Pszczelnictwa w Puławach Instytutu Sadownictwa i Kwiaciarstwa im. S. Pieniążka w Skierniewicach oraz analizy rynkowe Instytutu Ekonomiki, Rolnictwa i Gospodarki Żywnościowej - Państwowego Instytutu Badawczego (IERiGŻ-PIB). 


\section{Produkcja miodu w Unii Europejskiej}

Wielkość produkcji miodu w latach 2001-2013 w krajach UE przeanalizowano na podstawie danych Faostat z 2015 roku. Kraje te (uwzględniono 25 krajów, dla których podano dane w Faostat) podzielono na trzy kategorie w zależności od wielkości produkcji miodu. W tabeli 1 zaprezentowano kraje o największej produkcji (powyżej 10 tys. t rocznie). Grupę dużych producentów stanowiły następujące kraje (kolejność ze względu na wielkość produkcji w 2013 r.): Hiszpania, Rumunia, Węgry, Niemcy, Polska, Grecja, Francja i Bułgaria. Zaprezentowane dane wskazują na ciągłe przywództwo Hiszpanii wśród producentów miodu w UE, aczkolwiek w badanym okresie nie nastąpiła znacząca zmiana w wielkości produkcji. Rumunia i Bułgaria w badanym okresie dynamicznie zwiększyły produkcję miodu (Rumunia z 12,6 tys. t w 2001 r. do 26,7 tys. t w 2013 r., a Bułgaria z 4,9 tys. do 10,0 tys. t). W obu tych krajach produkcja miodu wzrosła w badanym okresie o ponad $100 \%$, więc można mówić o dynamicznym rozwoju pszczelarstwa w tych krajach.

Największe spadki w produkcji miodu odnotowano w Niemczech $(-40 \%)$ oraz we Francji (-20,6\%).

Wśród największych producentów miodu znalazła się również Polska, a jej udziały w tej grupie systematycznie rosły od 7,17\% (tj. 9,5 tys. t) w 2001 roku do 12,20\% w 2013 roku (blisko 15,5 tys. t). Wzrosła produkcja miodu w Polsce w badanym okresie o 5970 t (o 62,7\%). Oba zaprezentowane wyniki ilustrujące wielkość produkcji miodu są dla Polski bardzo korzystne. Pokazują ogólny wzrost wielkości produkowanego miodu, ale także rosnące udziały w grupie dużych producentów. Znaczny potencjał sektora pszczelarskiego w Polsce potwierdzają również analizy przeprowadzone przez Semkiwa [2014] oraz Semkiwa i Ochala [2009].

W całej badanej grupie wystąpił niewielki wzrost produkcji (średnioroczne tempo wzrostu wyniosło 0,009\%), a właściwie jej stagnacja. Na tym tle jeszcze lepiej widać rosnącą pozycję Polski wśród dużych producentów miodu w UE.

Do grupy małych producentów miodu zaliczono te kraje, w których wielkość produkcji miodu nie przekroczyła 3,4 tys. t rocznie (tab. 2). Największe udziały w grupie małych producentów miodu miały w 2013 roku Szwecja, Chorwacja i Belgia. W latach 2001-2013 największy wzrost produkcji miodu odnotowano w Estonii (o 236,4\%), Belgii (o 89,3\%), na Łotwie (o 89,7\%) oraz Litwie (o 71,4\%). Średnioroczne tempo wzrostu produkcji miodu w grupie małych producentów w badanym okresie wyniosło $2,93 \%$. Największy roczny przyrost produkcji miodu nastapił w 2004 roku w stosunku do roku poprzedniego (o 23,56\%), a największy jej spadek w 2007 roku w stosunku do roku poprzedniego (o $12,53 \%$ ). Duża niestabilność wielkości produkcji miodu w grupie małych 


\begin{tabular}{|c|c|c|c|c|c|c|c|c|c|c|}
\hline & $\stackrel{m}{\circ}$ & $\begin{array}{l}1 \\
8 \\
8 \\
0 \\
0\end{array}$ & 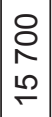 & $\begin{array}{l}8 \\
8 \\
10 \\
-\end{array}$ & $\begin{array}{l}m \\
\bar{\sigma} \\
0 \\
m\end{array}$ & $\begin{array}{l}\underset{J}{J} \\
\check{\tau}\end{array}$ & $\begin{array}{l}8 \\
i 0 \\
\infty \\
\infty\end{array}$ & 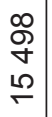 & 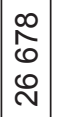 & $\begin{array}{l}\infty \\
\text { مొ } \\
\text { Ñ} \\
\end{array}$ \\
\hline & $\stackrel{\sim}{\sim}$ & $\begin{array}{l}0 \\
\infty \\
\sigma \\
\sigma\end{array} \mid$ & 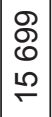 & $\begin{array}{l}\stackrel{8}{0} \\
\infty \\
\forall \\
\square\end{array}$ & $\begin{array}{l}10 \\
\Gamma \\
N \\
\mathcal{N}\end{array}$ & $\begin{array}{l}\bar{N} \\
F\end{array}$ & $\begin{array}{l}8 \\
10 \\
\end{array}$ & $\begin{array}{l}0 \\
\frac{0}{\sigma} \\
\stackrel{2}{\simeq}\end{array}$ & $\begin{array}{l}\tilde{\Xi} \\
0 \\
\tilde{N}\end{array}$ & $\begin{array}{l}\frac{0}{\infty} \\
\\
\end{array}$ \\
\hline & $\underset{\sim}{\stackrel{\sim}{\circ}}$ & 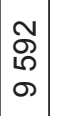 & \begin{tabular}{|l|}
$\tilde{\infty}$ \\
$\infty$ \\
$\infty$ \\
$\sim$ \\
$N$
\end{tabular} & $\begin{array}{l}8 \\
8 \\
0 \\
\forall \\
\square\end{array}$ & 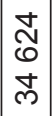 & 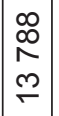 & $\begin{array}{l}8 \\
10 \\
1\end{array}$ & \begin{tabular}{l}
$\mathscr{8}$ \\
$\mathbb{m}$ \\
$m$ \\
\hdashline
\end{tabular} & 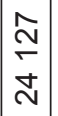 & $\begin{array}{l}\stackrel{N}{N} \\
\hat{N} \\
\end{array}$ \\
\hline & 응 & $\begin{array}{l}2 \\
0 \\
0 \\
0 \\
ㅇ\end{array}$ & $\begin{array}{l}\infty \\
\stackrel{\infty}{N} \\
\stackrel{n}{N}\end{array}$ & 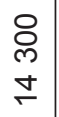 & 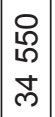 & $\begin{array}{l}\underset{\sim}{\sim} \\
\infty \\
\stackrel{m}{\sim}\end{array}$ & $\begin{array}{l}8 \\
10 \\
6 \\
0\end{array}$ & $\begin{array}{c}\hat{o} \\
\dot{o} \\
\stackrel{N}{\sim}\end{array}$ & $\begin{array}{l}\mathcal{N} \\
\mathbb{N} \\
\mathbb{N}\end{array}$ & $\begin{array}{l}\hat{8} \\
\text { mे } \\
\end{array}$ \\
\hline$\mp$ & ஓ् & $\begin{array}{l}\mathscr{N} \\
\tilde{N} \\
\sigma\end{array}$ & $\begin{array}{l}0 \\
0 \\
+ \\
0 \\
-\end{array}$ & $\begin{array}{l}\stackrel{8}{0} \\
\circ \\
\wp\end{array}$ & $\mid \begin{array}{c}0 \\
\tilde{m} \\
\tilde{m} \\
\tilde{m}\end{array}$ & $\begin{array}{l}\hat{N} \\
\hat{N} \\
م \\
\sim\end{array}$ & 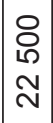 & $\begin{array}{l} \\
0 \\
\vdots \\
\square \\
\end{array}$ & \begin{tabular}{|l|}
$\hat{\sigma}$ \\
$\sigma$ \\
$\sigma$ \\
$\sigma$
\end{tabular} & 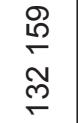 \\
\hline$\frac{\bar{\sigma}}{\frac{1}{1}}$ & $\stackrel{\infty}{\stackrel{D}{~}}$ & $\begin{array}{l}\hat{N} \\
m \\
F\end{array}$ & $\begin{array}{l}\hat{N} \\
\hat{N} \\
\sim \\
\sim\end{array}$ & $\begin{array}{l}\mathbb{1} \\
0 \\
0 \\
L \\
\sim\end{array}$ & \begin{tabular}{|l}
$\bar{\phi}$ \\
$\tilde{\rho}$ \\
$\bar{m}$
\end{tabular} & $\begin{array}{l}\bigotimes \\
\infty \\
\varpi \\
\leftarrow\end{array}$ & $\begin{array}{l}\text { J్ల } \\
\text { స̃ }\end{array}$ & $\begin{array}{l}\hat{8} \\
\pm \\
\square\end{array}$ & 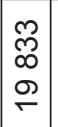 & 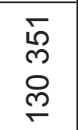 \\
\hline 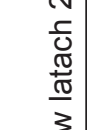 & 용 & $\begin{array}{l}9 \\
\stackrel{9}{c} \\
\omega\end{array}$ & $\begin{array}{l}\mathscr{Q} \\
\stackrel{2}{ } \\
\infty \\
\leftarrow\end{array}$ & 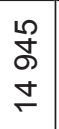 & $\begin{array}{l}0 \\
\$ \\
\infty \\
\bar{m}\end{array}$ & $\begin{array}{l}8 \\
8 \\
0 \\
-\end{array}$ & 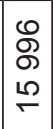 & 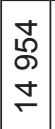 & $\mid \begin{array}{l}\hat{0} \\
2 \\
0 \\
-\end{array}$ & $\begin{array}{l}\text { N } \\
\text { ల } \\
\text { ్ }\end{array}$ \\
\hline $\bar{\Phi}$ & $\stackrel{\text { ஜ }}{\stackrel{\sim}{2}}$ & $\begin{array}{l}\stackrel{9}{\circ} \\
\stackrel{0}{\circ}\end{array}$ & 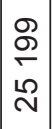 & $\begin{array}{l}\infty \\
\grave{N} \\
\omega\end{array}$ & $\mid \begin{array}{l}\overline{0} \\
\overline{8} \\
\bar{m}\end{array}$ & $\begin{array}{l}m \\
\infty \\
m \\
m \\
-\end{array}$ & $\begin{array}{l}\frac{D}{\infty} \\
\stackrel{m}{\sigma}\end{array}$ & 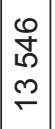 & \begin{tabular}{|l|}
$\stackrel{2}{\circ}$ \\
$\stackrel{2}{ }$ \\
$\infty$ \\
$\sim$
\end{tabular} & $\begin{array}{l}\underset{1}{\infty} \\
\vdots \\
\stackrel{N}{N} \\
\stackrel{N}{N}\end{array}$ \\
\hline $\begin{array}{l}\text { Ш } \\
: \overline{\bar{\nu}} \\
\end{array}$ & ஜి & $\begin{array}{l}\bar{N} \\
\mp\end{array}$ & $\begin{array}{l}\tilde{N} \\
\stackrel{N}{N} \\
\bar{N}\end{array}$ & $\begin{array}{l}\hat{S} \\
\stackrel{N}{\sigma} \\
\mathscr{O}\end{array}$ & $\begin{array}{l}0 \\
\stackrel{P}{N} \\
N\end{array}$ & $\begin{array}{l}10 \\
\mathscr{8} \\
10 \\
12\end{array}$ & $\begin{array}{l}\stackrel{T}{T} \\
\stackrel{T}{\sigma} \\
\end{array}$ & \begin{tabular}{|l|}
$م$ \\
$\qquad$ \\
$\sigma$ \\
$\sigma$ \\
$\sigma$
\end{tabular} & \begin{tabular}{l}
$\stackrel{0}{0}$ \\
N \\
$o$ \\
\hdashline
\end{tabular} & $\begin{array}{l}\stackrel{M}{N} \\
\stackrel{M}{N} \\
\stackrel{N}{N}\end{array}$ \\
\hline $\begin{array}{l}3 \\
0 \\
0 \\
0 \\
0 \\
0 \\
0 \\
0\end{array}$ & $\begin{array}{l}\text { ণ } \\
\text { ণ }\end{array}$ & $\begin{array}{l}8 \\
\varnothing \\
\infty\end{array}$ & $\begin{array}{l}10 \\
10 \\
12 \\
20 \\
N\end{array}$ & $\begin{array}{l}\mp \\
\sigma \\
\stackrel{\sigma}{\sigma}\end{array}$ & $\begin{array}{l}\stackrel{\Sigma}{N} \\
\dot{m}\end{array}$ & $\begin{array}{l}\varrho \\
\infty \\
\leftarrow \\
\leftarrow\end{array}$ & 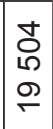 & $\begin{array}{l}\hat{2} \\
\Omega \\
F \\
F\end{array}$ & $\mid \begin{array}{l}0 \\
\frac{10}{6} \\
0 \\
\end{array}$ & 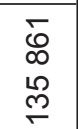 \\
\hline . & రి & $\begin{array}{l}8 \\
0 \\
\infty \\
\infty\end{array}$ & $\begin{array}{l}\bar{\delta} \\
\varnothing \\
\end{array}$ & $\begin{array}{l}8 \\
8 \\
10 \\
-\end{array}$ & $\begin{array}{l}\Omega \\
N \\
N \\
b \\
m\end{array}$ & $\begin{array}{l}8 \\
8 \\
10 \\
2\end{array}$ & 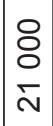 & 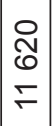 & 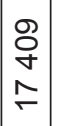 & $\begin{array}{l}\text { の } \\
\stackrel{\operatorname{s}}{\leftarrow} \\
\stackrel{\infty}{+}\end{array}$ \\
\hline $\begin{array}{l}\frac{0}{2} \\
\frac{2}{2} \\
\text { 엉 }\end{array}$ & ণి & $\begin{array}{l}8 \\
\circ \\
\dot{y} \\
10\end{array}$ & 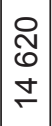 & $\begin{array}{c}8 \\
\\
12 \\
2\end{array}$ & $\begin{array}{l}\mathbb{N} \\
N \\
L \\
m\end{array}$ & $\begin{array}{l}\stackrel{O}{0} \\
\stackrel{N}{0} \\
\bullet \\
-\end{array}$ & 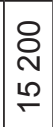 & $\mid \begin{array}{l}\text { J } \\
0 \\
\sigma\end{array}$ & 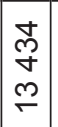 & 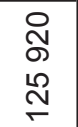 \\
\hline 궁 & ¿ & $\begin{array}{l}\bar{乃} \\
\delta \\
\forall\end{array}$ & 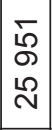 & $\begin{array}{l}\tilde{N} \\
0 \\
\end{array}$ & $\begin{array}{l}\bar{\sigma} \\
\bar{\sigma} \\
\end{array}$ & $\begin{array}{l}m \\
\infty \\
\infty \\
\mathscr{D} \\
\sim\end{array}$ & $\begin{array}{l}\hat{n} \\
m \\
i \\
\sim\end{array}$ & 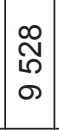 & $\mid \begin{array}{l}\infty \\
0 \\
i \\
\stackrel{2}{\sim}\end{array}$ & $\begin{array}{l}\hat{N} \\
\text { o } \\
\text { N } \\
\stackrel{2}{\sim}\end{array}$ \\
\hline 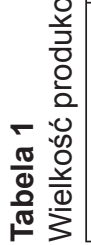 & 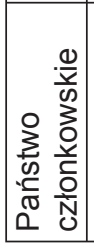 & 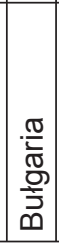 & 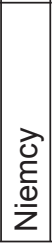 & $\begin{array}{l}\frac{\pi}{0} \\
\frac{\mathbb{D}}{0} \\
0\end{array}$ & 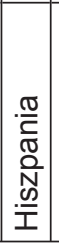 & 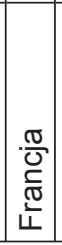 & $\begin{array}{l}3 \\
0 \\
0 \\
3\end{array}$ & 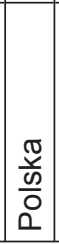 & 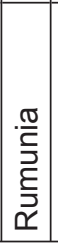 & 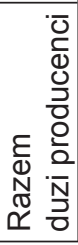 \\
\hline
\end{tabular}




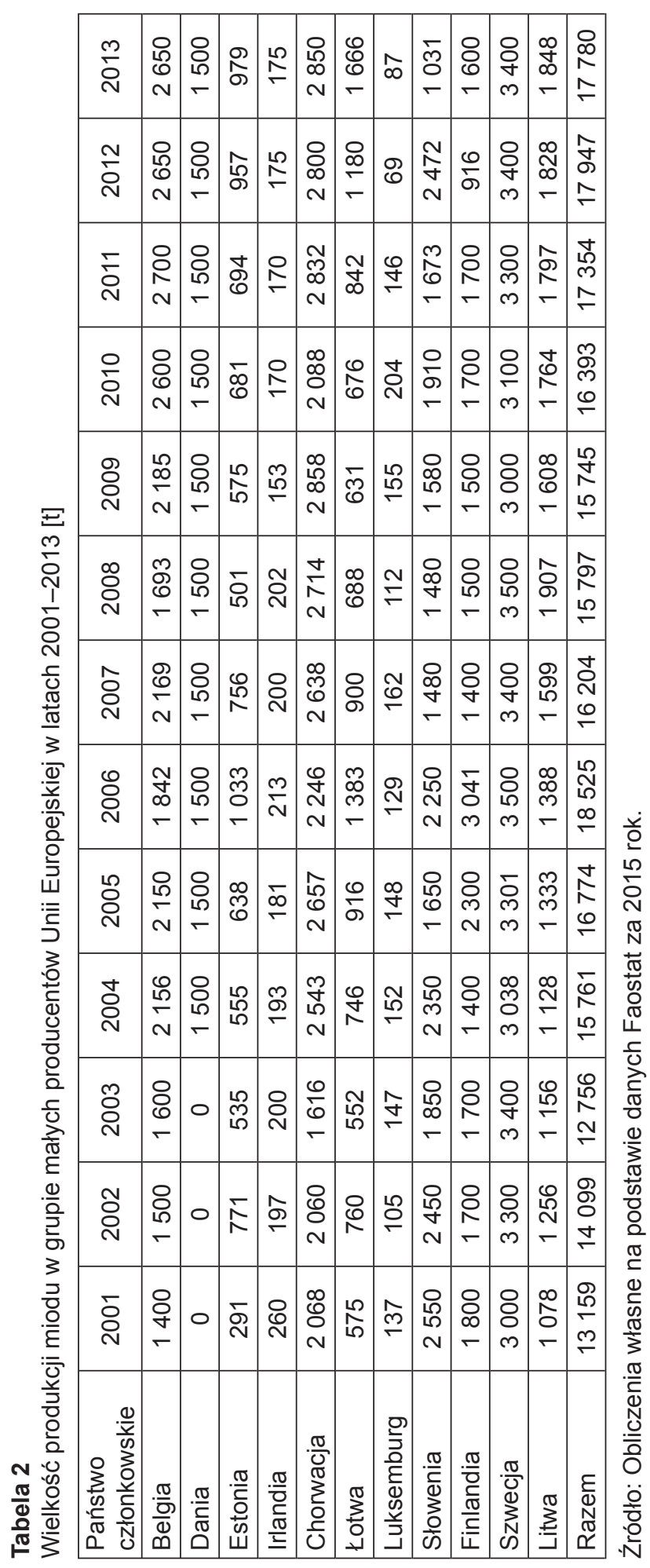




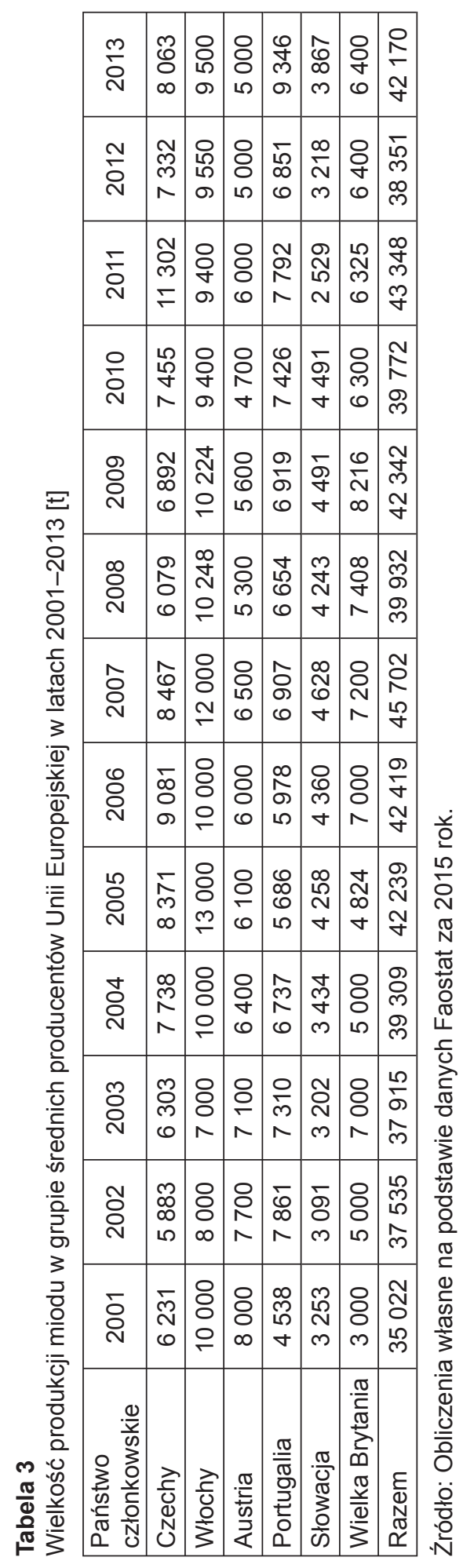


producentów UE wskazuje na niepewność i bardzo silne reakcje producentów na sytuację rynkową. Optymizmem napawa największe spośród analizowanych grup średnioroczne tempo wzrostu produkcji miodu.

Do grupy średnich producentów miodu zaliczono te kraje, w których wielkość produkcji miodu nie przekroczyła 10 tys. $t$ rocznie, ale była większa od 3,4 tys. t (tab. 3). Grupa ta charakteryzowała się średniorocznym wzrostem produkcji miodu w latach 2001-2013 wynoszącym 1,85\%. Największymi producentami miodu w 2013 roku w grupie średnich producentów UE były Włochy, Portugalia i Czechy. Największy wzrost wielkości produkcji odnotowano w Wielkiej Brytanii (o 113,3\%) i Portugalii (o 105,9\%), przy wzroście dla całej grupy wynoszącym $20,4 \%$ (rok $2001=100)$.

\section{Wsparcie dla producentów miodu w Unii Europejskiej}

Możliwość stosowania pomocy w sektorze pszczelarskim w UE przewiduje art. 55 rozporządzenia Parlamentu Europejskiego i Rady (UE) 1308/2013. Działania te mogą być realizowane przez kraje UE na podstawie zatwierdzonych przez Komisję Europejską trzyletnich krajowych programów wsparcia pszczelarstwa.

Warto także odnotować, że od 2007 roku stale wzrasta wartość środków UE przeznaczonych dla sektora pszczelarskiego na cele związane ze zwiększeniem liczby uli i wynikające z rosnących potrzeb sektora pszczelarskiego. W 2011 roku przekroczono kwotę $32 \mathrm{mln}$ euro na roczny budżet dla tego sektora [European Commission 2013b], a w latach 2014-2016 osiagnięto poziom 33,1 mln euro [European Commission 2013a].

Największe udziały $w$ tych funduszach mają: Hiszpania (16,2\%), Francja $(10,7 \%)$, Rumunia $(10,1 \%)$, Włochy i Grecja (po 6,5\%) oraz Polska $(8,3 \%)$. Łącznie najwięksi beneficjanci (6 państw) partycypują w funduszach unijnych wspierających działalność pszczelarską w $62,5 \%$. Wskazuje to na większe możliwości rozwojowe tego sektora w państwach korzystających z dotacji unijnych.

W Polsce w 2016 roku Agencja Rynku Rolnego (ARR) zrealizowała trzecią część trzyletniego Krajowego Programu Wsparcia Pszczelarstwa w Polsce w latach 2013/14; 2014/15; 2015/16. Wydatki ponoszone w ramach programu są finansowane po $50 \% \mathrm{z}$ budżetu UE i krajowego. Pomoc finansowa w sektorze pszczelarskim jest udzielana w celu poprawy warunków produkcji i zbytu oraz jakości produktów pszczelich. W szczególności popierana była pomoc techniczna skierowana do pszczelarzy i grup pszczelarzy w zakresie zwalczania warozy, racjonalizacji sezonowego przenoszenia uli, wsparcia laboratoriów przeprowadzających analizy dotyczące fizykochemicznych właściwości miodu oraz wsparcia zasiedlania uli na terenie krajów członkowskich UE [IERiGŻ 2016]. 


\section{Konsumpcja miodu w krajach członkowskich}

Popyt na miód, ze względu na jego liczne walory, na rynku europejskim ciagle rośnie. Pokrycie popytu powoduje poszukiwanie nowych możliwości jego zaspokojenia, a więc oczywiście nowych dostawców, ale przede wszystkim wykorzystanie istniejącego potencjału produkcji wśród tutejszych producentów tego surowca. Służyć temu mają wszelkie działania sprzyjające zwiększeniu produkcji, a w tym również unijne programy pszczelarskie.

Tabela 4

Konsumpcja miodu w krajach UE w latach 2009, 2011 i 2013 (kg/osobę/rok)

\begin{tabular}{|l|c|c|c|}
\hline Państwo członkowskie & 2009 & 2011 & 2013 \\
\hline Belgia & 1,67 & 1,98 & 2,23 \\
\hline Bułgaria & 1,27 & 1,26 & 1,35 \\
\hline Czechy & 0,7 & 1,16 & 0,82 \\
\hline Dania & 0,32 & 0,23 & 0,23 \\
\hline Niemcy & 0,94 & 0,95 & 0,83 \\
\hline Estonia & 0,43 & 0,52 & 0,74 \\
\hline Irlandia & 0,18 & 0,27 & 0,16 \\
\hline Grecja & 1,43 & 1,28 & 1,41 \\
\hline Hiszpania & 0,81 & 0,98 & 1,08 \\
\hline Francja & 0,32 & 0,33 & 0,22 \\
\hline Chorwacja & - & - & 0,71 \\
\hline Włochy & 0,28 & 0,26 & 0,23 \\
\hline Łotwa & 0,33 & 0,55 & 0,92 \\
\hline Litwa & 0,50 & 0,62 & 0,79 \\
\hline Luksemburg & 0,31 & 0,28 & 0,16 \\
\hline Węgry & 2,18 & 1,64 & 1,76 \\
\hline Austria & 0,87 & 0,90 & 0,87 \\
\hline Polska & 0,47 & 0,51 & 0,76 \\
\hline Portugalia & 0,64 & 0,73 & 0,88 \\
\hline Rumunia & 0,98 & 1,17 & 1,33 \\
\hline Słowenia & 0,77 & 0,81 & 0,50 \\
\hline Słowacja & 0,87 & 0,48 & 0,88 \\
\hline Finlandia & 0,30 & 0,31 & 0,31 \\
\hline Szwecja & 0,32 & 0,35 & 0,38 \\
\hline Wielka Brytania & 0,49 & 0,52 & 0,58 \\
\hline Zrofia & & & \\
\hline
\end{tabular}

Źródło: Opracowanie własne na podstawie danych Faostat z 2016 roku. 
Zaprezentowana charakterystyka wielkości produkcji miodu oraz wykorzystywania funduszy unijnych na programy pszczelarskie pośrednio ilustruje potencjał produkcyjny poszczególnych krajów. Ma to wpływ na poziom konsumpcji miodu w poszczególnych państwach, przyczyniając się do zwiększonej jego podaży. W tabeli 4 zaprezentowano spożycie miodu $\mathrm{w} \mathrm{kg} / \mathrm{osobe} / \mathrm{rok} \mathrm{w}$ latach 2009, 2011 i 2013. Do obliczenia wielkości konsumowanego miodu posłużono się następującą formułą: do wielkości produkcji w danym roku i kraju dodano wielkość importu i odjęto wielkość eksportu. Otrzymaną wielkość odniesiono do liczby mieszkańców danego kraju.

Liderami w spożyciu miodu [kg/osobę/rok] w 2013 roku były: Belgia $(2,23)$, Węgry $(1,76)$, Grecja $(1,41)$, Bułgaria $(1,35)$, Rumunia $(1,33)$ i Hiszpania $(1,08)$. Dynamika zmian w spożyciu miodu w badanych krajach i latach była zróżnicowana. Porównując okres pięcioletni, a więc odnosząc konsumpcję miodu w 2013 roku do 2009 roku, można stwierdzić, że największy wzrost odnotowano tam, gdzie działają mali producenci korzystający z dotacji unijnych, czyli na Łotwie (o 179\%), w Estonii (o 72\%), Polsce (o 62\%) oraz na Litwie (o 58\%).

Za pozytywną zmianę należy uznać wzrost spożycia miodu na osobę na rok także w krajach, w których działają więksi producenci miodu. W badanym okresie dynamiczny wzrost odnotowano w takich krajach, jak: Belgia (wzrost o 0,56 $\mathrm{kg} /$ osobę/rok w 2013 r. w stosunku do 2009 r.), Rumunia (wzrost o 0,35) oraz Hiszpania (wzrost o 0,27). Spadek konsumpcji miodu zaobserwowano w Luksemburgu, Słowenii, Danii oraz na Węgrzech.

\section{Podsumowanie}

Nowe trendy $\mathrm{w}$ zachowaniach konsumenckich związane $\mathrm{z}$ wyborem produktów spożywczych wyznaczają wyzwania dla współczesnego rynku. Wzrost znaczenia jakości i bezpieczeństwa żywności w decyzjach nabywczych konsumentów w Polsce [Jeznach 2008, Jeznach 2014] oraz w krajach UE stanowi przesłankę do rozwoju tych rynków produktów spożywczych, które mając potencjał rozwojowy, wpisują się w zaspokojenie potrzeb konsumentów. Przykładem takiego rynku w UE jest rynek miodu.

Zaprezentowana analiza danych dotycząca wielkości produkcji miodu w latach 2001-2013 wskazuje na znaczny potencjał wzrostowy małych i średnich producentów. Zastosowane subwencje dla pszczelarzy w krajach UE pozwalają nadal wspierać wszelkie formy pomocy technicznej dla tej działalności.

Głównie za sprawą małych producentów (poza Polską), którzy korzystali ze wsparcia na fundusze pszczelarskie oraz wykorzystywali korzystne do hodowli 
pszczół naturalne warunki przyrodniczo-ekonomiczne, doszło do zwiększenia krajowego spożycia miodu. Zaobserwowany, znaczny wzrost spożycia miodu w Polsce pozwala wnioskować, że podobne pozytywne zmiany zajdą również u większych producentów miodów. Należy jednak kontynuować badania w kierunku preferencji konsumentów miodu.

\section{Literatura}

BOROWSKA A., 2011: Ksztaltowanie się światowego rynku miodu w latach 1961-2010, Roczniki Nauk Rolniczych, Seria G 98 (3), 160-175.

European Commission, 2013a: Green light for 2014-2016 beekeeping programmes, Agriculture and Rural Development News, www.ec.europa.eu/agriculture/newsroom/121 en.htm [dostęp: 15.06.2016].

European Commission, 2013b: Sprawozdanie Komisji dla Parlamentu Europejskiego i Rady dotyczqce wdrażania środków na rzecz sektora pszczelarskiego określonych w rozporzqdzeniu Rady (WE) nr 1234/2007 COM(2013)593, http://eur-lex.europa.eu/resource. html?uri=cellar:61 cb9a35-08b6-11e3-a35201aa75ed71a1.0008.05/DOC_1\&forma$\mathrm{t}=\mathrm{PDF}$ [dostęp: 14.06.2016].

GUS, 2001-2013: Budzety gospodarstw domowych, Zakład Wydawnictw Statystycznych, Warszawa.

IERiGŻ, 2016: Rynek cukru. Stan i perspektywy, Analizy Rynkowe 43.

JEZNACH M., 2008: Uwarunkowania ekonomiczno-organizacyjne jakości i bezpieczeństwa żywności, Wydawnictwo SGGW, Warszawa.

JEZNACH M., 2014: Jakość żywności i jej wyróżniki w ocenie konsumentów, Wydawnictwo SGGW, Warszawa.

SEMKIW P., 2014: Sektor pszczelarski w Polsce w 2014 roku, Instytut Ogrodnictwa, Zakład Pszczelnictwa w Puławach, Puławy.

SEMKIW P., OCHAL J., 2009: Analiza sektora pszczelarskiego w Polsce dla opracowania Krajowego Programu Wsparcia Pszczelarstwa w latach 2010-2013, Instytut Sadownictwa i Kwiaciarstwa im. Szczepana Pieniążka w Skierniewicach, Oddział Pszczelnictwa w Puławach, Puławy.

\section{Abstrakt}

W artykule zaprezentowano zmiany na rynku miodu w krajach UE w latach 2001-2013. Zastosowano metodę podziału producentów miodu ze względu na wielkość produkcji na: dużych, średnich i małych. Najbardziej dynamicznie rosła produkcja miodu w grupie małych producentów, w której średnioroczne tempo wzrostu wyniosło 2,93\% w badanym okresie. Stwierdzono dużą niestabilność wielkości produkcji miodu w UE, co wskazuje na niepewność i bardzo silne reakcje producentów na sytuację rynkową. Za zasadne uznano więc wsparcie dla 
programów pszczelarskich, gdyż przyczynia się ono do wzrostu produkcji oraz konsumpcji miodu w poszczególnych krajach.

Slowa kluczowe: miód, produkcja, spożycie

\title{
The honey market in the European Union in the period 2001-2013
}

\begin{abstract}
The article presents changes in honey production in the countries of EU in years 2001-2013. The method used in the article divided honey producers by size of the production: large, medium and small. Honey production in the group of small producers was the most dynamically growing, where the average annual growth rate was $2.93 \%$ in the considered period. Identified large volatility of honey production in the EU, which indicates the uncertainty and strong reactions of producers to the market situation. Therefore it is very important to support apiculture programs as contribution to the increasing of honey production and consumption in the respective countries.
\end{abstract}

Key words: honey, production, consumption 